\title{
SEAFARERS HOSPITAL SOCIETY LAUNCHES ORAL HEALTH INITIATIVE FOR SCHOOLCHILDREN
}

Respected maritime health and welfare charity the Seafarers Hospital Society (SHS) was in Newlyn School recently to launch its latest initiative for fishing families. For the next five years SHS is funding oral health education for children aged 5-9 in Newlyn School, at the heart of the Cornish fishing community.

Working with community dental provider Smile Together who deliver Brighter Smiles, Cornwall's oral health programme, the Society will be funding dedicated support in Newlyn School, including:

- Daily tooth brushing clubs for nursery and reception classes

- Free fluoride varnishing for reception and year 1 to protect against tooth decay

- Education and advice for all children, staff and parents/carers to establish good eating habits and limit sugary snacks and drinks
- Home education packs for every child to help establish good practice at home

- A dedicated dental nurse to work with teachers and classroom staff.

Children and staff were given a taste of the Brighter Smiles programme with a mini oral health education session delivered by Jo Trevelyan, Lead Oral Health Nurse from Smile Together. Speaking after the event Jo said: 'We are thrilled to be delivering our oral health programme in Newlyn School thanks to this generous and long term financial commitment from Seafarers Hospital Society. The pupils responded really well to the session and asked some great questions. We met many of them in June when we brought our Smiles at Sea mobile dental unit to the school and they are really enthusiastic to

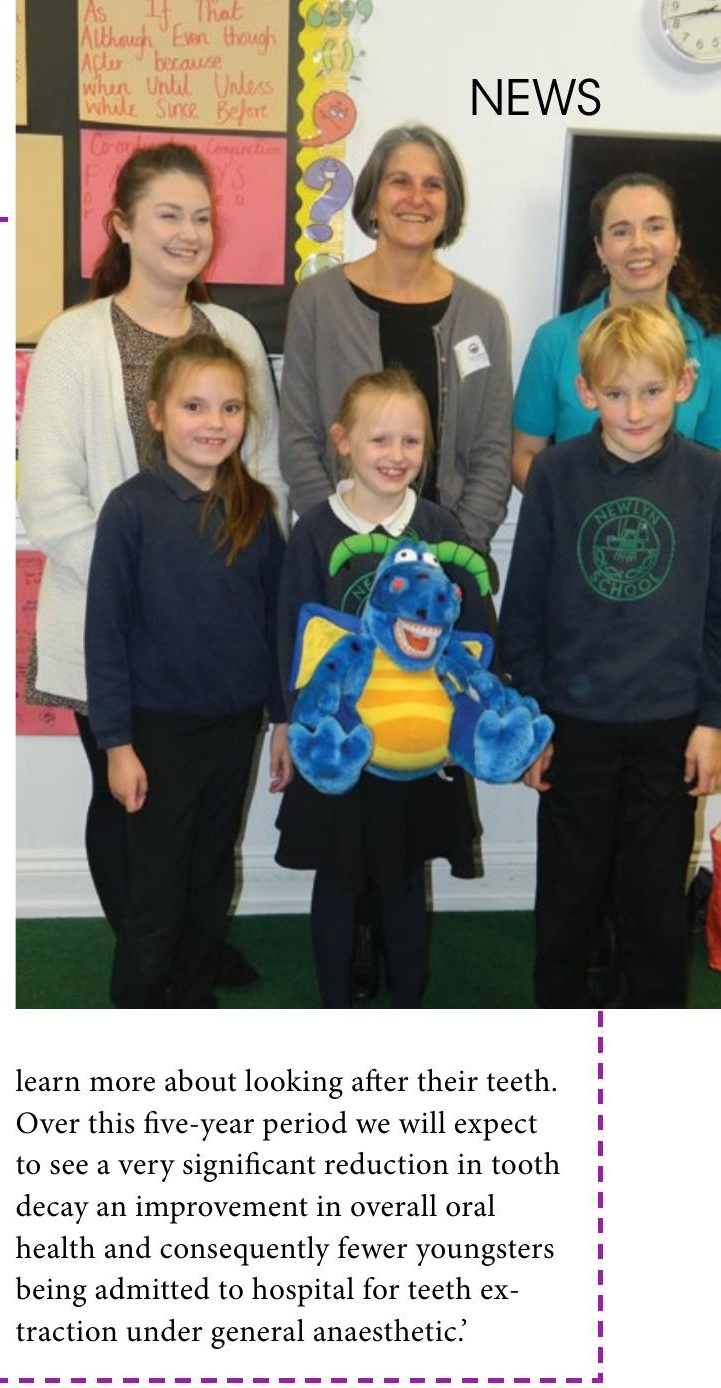

\section{A RELEVANT AND DIVERSE PROGRAMME FOR DENTAL HYGIENISTS AND THERAPISTS}

The British Dental Conference and Dentistry Show 2020 will once again present the Hygienist \& Therapist Symposium, with two days of lectures dedicated to those in this area of the profession. To ensure the relevance and diversity of the programme, both the British Society of Dental Hygiene and Therapy (BSDHT) and the British Association of Dental Therapists (BADT) will be supporting the Symposium.

Julie Deverick, President of the BSDHT, discusses why the Society was happy to be involved with the event for another year: 'The conference is a great platform for both members and non-members to come and chat to us and discuss any issues they are experiencing face-to-face. Even if people feel like their query or concern isn't big enough to call our office about, meeting in person often makes it easier to have a conversation so we can offer guidance or signpost them as appropriate.

'The BSDHT will also be hosting the Hygienist \& Therapist Symposium on Friday, for which we have gathered several well- known speakers. They will cover various interesting topics that are all pertinent to delegates' working lives. We quality assure all the presentations to ensure that the messages being communicated are correct and that they match the proper GDC learning outcomes.'

The Hygienist \& Therapist Symposium at the British Dental Conference and Dentistry Show will offer plenty of support for professionals looking to advance their careers. In addition, the event will offer the opportunity for dental hygienists and dental therapists to learn more about other areas that might be of interest to them, such as practice management. This provides a greater understanding of different roles in the practice and could help dental hygienists and dental therapists to better utilise their capabilities among the team. It also offers a chance for professionals to widen their scope.

These events are also ideal for reflective learning, encouraging delegates to think about what they do in practice compared to

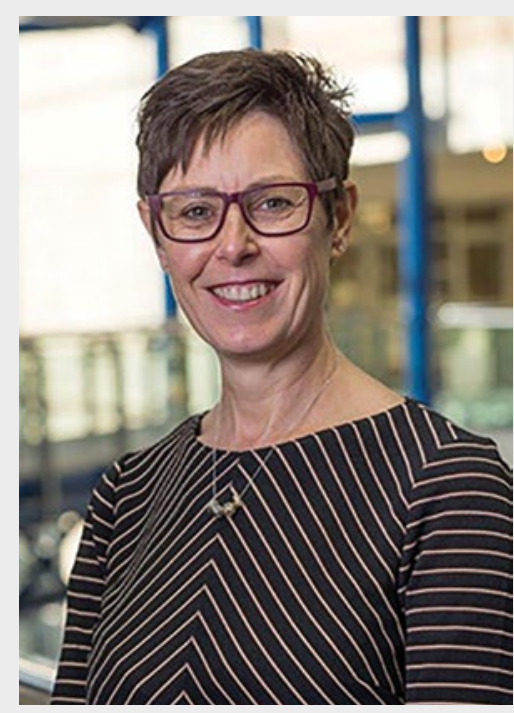

what is being discussed with trade experts or during lectures.

The British Dental Conference and Dentistry Show 2020 will be held on Friday 15 and Saturday 16 May at Birmingham NEC. For all the latest information, visit www.thedentistryshow.co.uk. 